\title{
AARC Clinical Practice Guideline: Management of Adult Patients With Oxygen in the Acute Care Setting
}

\author{
Thomas Piraino, Maria Madden, Karsten J Roberts, James Lamberti, \\ Emily Ginier, and Shawna L Strickland
}

\author{
Introduction \\ Committee Composition \\ Search Strategy \\ Study Selection \\ Development of Recommendations \\ Assessment and Recommendations \\ Specific Oxygenation Targets in Acutely Ill Adults \\ Specific Oxygenation Targets in Critically Ill Adults \\ Postoperative Continuous Monitoring \\ Early Initiation of High-Flow Nasal Cannula \\ High-Flow Nasal Cannula Versus Standard Oxygen \\ Humidification of Oxygen \\ Summary
}

Providing supplemental oxygen to hospitalized adults is a frequent practice and can be administered via a variety of devices. Oxygen therapy has evolved over the years, and clinicians should follow evidence-based practices to provide maximum benefit and avoid harm. This systematic review and subsequent clinical practice guidelines were developed to answer questions about oxygenation targets, monitoring, early initiation of high-flow oxygen (HFO), benefits of HFO compared to conventional oxygen therapy, and humidification of supplemental oxygen. Using a modification of the RAND/UCLA Appropriateness Method, 7 recommendations were developed to guide the delivery of supplemental oxygen to hospitalized adults: (1) aim for $\mathrm{S}_{\mathrm{pO}_{2}}$ range of $94-98 \%$ for most hospitalized patients (8892\% for those with COPD), (2) the same $\mathrm{S}_{\mathrm{pO}_{2}}$ range of 94-98\% for critically ill patients, (3) promote early initiation of HFO, (4) consider HFO to avoid escalation to noninvasive ventilation, (5) consider HFO immediately postextubation to avoid re-intubation, (6) either HFO or conventional oxygen therapy may be used with patients who are immunocompromised, and (7) consider humidification for supplemental oxygen when flows $>4 \mathbf{L} / \mathbf{m i n}$ are used. Key words: oxygen; adult; high flow; oxygenation. [Respir Care 2022;67(1):115-128. (C) 2022 Daedalus Enterprises]

\section{Introduction}

Adult patients admitted to critical care services for acute respiratory failure often require supplemental oxygen. ${ }^{1}$ Generally thought to be harmless, there is an increasing interest in the potentially harmful effects of oxygen delivery and excessive $\mathrm{F}_{\mathrm{IO}_{2}}{ }^{1,2}$ Various oxygen delivery devices are used, and selection is often based on comfort and the level of supplemental oxygen needed. When escalation in care is required, high-flow nasal cannula (HFNC) can be used to potentially avoid noninvasive or invasive mechanical ventilation. ${ }^{3-8}$

Available evidence shows varying outcomes for supplemental oxygen therapy in adult acute and intensive care. In a systematic review of 25 randomized control trials (RCTs), Chu et $\mathrm{al}^{1}$ reported increased mortality with liberal 


\section{AarC Clinical Practice Guideline: Managing Oxygen in Acute Care}

use of oxygen in ICU subjects. Their review suggested unfavorable outcomes as a result of $\mathrm{S}_{\mathrm{pO}_{2}}>94-96 \%$.

Our literature review focused on monitoring and methods of oxygen delivery. The clinical practice guidelines were developed from our review to address 6 questions regarding oxygen therapy in postoperative and critical care:

1. In adult patients requiring supplemental oxygen, does a specific oxygenation target improve hospital length of stay (LOS), ICU LOS, mortality, and cognitive function?

2. In critically ill adult patients requiring supplemental oxygen, does a specific oxygenation target improve hospital LOS, ICU LOS, mortality, and cognitive function?

3. In adult patients receiving postoperative supplemental oxygen, does continuous monitoring prevent adverse events compared to intermittent or no monitoring?

4. In adult patients requiring supplemental oxygen, does early initiation of HFNC decrease hospital LOS, decrease ICU LOS, decrease escalation of care to invasive or noninvasive ventilation (NIV), and improve morbidity versus late initiation of high-flow oxygen?

5. In adult patients requiring supplemental oxygen, does HFNC decrease hospital LOS, decrease ICU LOS, decrease escalation of care to invasive ventilation or NIV, and decrease morbidity versus standard oxygen delivery?

6. In adult patients requiring supplemental oxygen, does heated or nonheated humidification of oxygen improve patient outcomes, improve patient comfort, and reduce adverse events versus no humidification?

Mr Piraino is affiliated with St. Michael's Hospital, Toronto Ontario. Ms Madden is affiliated with VERO Biotech, Atlanta, Georgia. Ms Roberts is affiliated with Hospital of the University of Pennsylvania, Philadelphia, Pennsylvania. Dr Lamberti is affiliated with Inova Fairfax Hospital, Department of Medicine, Fairfax, Virginia. Ms Ginier is affiliated with Taubman Health Sciences Library, University of Michigan, Ann Arbor, Michigan. Dr Strickland is affiliated with American Epilepsy Society, Chicago, Illinois; and Rush University, Chicago, Illinois.

Mr Piraino discloses relationships with Dräger, Fisher \& Paykel, and Philips. Ms Madden discloses relationships with ICON and Dräger. Dr Lamberti discloses relationships with Boehringer Ingelheim, Janssen, Sanofi/Regeneron, Philips, and Genentech. The remaining authors declare no conflicts of interest.

At the time of this work, Dr Strickland was affiliated with the American Association for Respiratory Care.

Supplementary material related to this paper is available at http://rc. rcjournal.com

Correspondence: Thomas Piraino RRT FCSRT FAARC, St. Michael's Hospital, 36 Queen St E, Toronto, ON M5B 1W8, Toronto, Canada.

E-mail: thomaspiraino@gmail.com.

DOI: $10.4187 /$ respcare.09294

\section{Committee Composition}

A committee was selected by the American Association for Respiratory Care (AARC) leadership based on their known experience related to the topic, their interest in participating in the project, and their commitment to the process details. The committee first met face to face, where they were introduced to the process of developing clinical practice guidelines. At that time, the committee selected a chair and wrote a first draft of patient, intervention, comparison, and outcome (PICO) questions. Subsequent meetings occurred as needed by conference call. Frequent e-mail communication occurred among committee members and AARC staff. The committee members received no remuneration for their participation in the process, though the AARC covered their face-to-face meeting expenses.

\section{Search Strategy}

A literature search was conducted using the PubMed, CINAHL via EBSCOhost, and Scopus.com databases for studies on oxygen therapy care in hospitalized adult patients. The search strategies used a combination of relevant controlled vocabulary (ie, Medical Subject Headings and CINAHL Headings) and key word variations related to oxygen therapy, oxygenation techniques, and outcomes. The searches were limited to English language studies about human populations. The searches were also designed to filter out citations indexed as commentaries, editorials, interviews, news, or reviews. No date restrictions were applied to the searches. Refer to the online supplemental material for available at http://rc.rcjournal.com the complete search strategy executed in each database on January 21, 2021. Duplicate citations were identified and removed using the EndNote X8 (Clarivate, Philadelphia, Pennsylvania) citation management software.

\section{Study Selection}

At least two reviewers assessed the eligibility in the Covidence (Melbourne, Australia) systematic review software. If there was disagreement regarding eligibility, a third reviewer would be used to resolve the dispute. Inclusion criteria used to assess eligibility were (1) oxygen therapy, (2) adult population, and (3) clinical outcomes. The exclusion criteria used were (1) not oxygen therapy, (2) pediatric population, (3) wrong route of oxygen administration, (4) no clinical outcomes relevant to oxygen therapy, (5) wrong setting, (6) not empirical research (eg, theory, opinion, or review articles), and (7) published prior to 1987.

\section{Development of Recommendations}

It is recognized that a process is necessary to combine the best available evidence with committee members' 


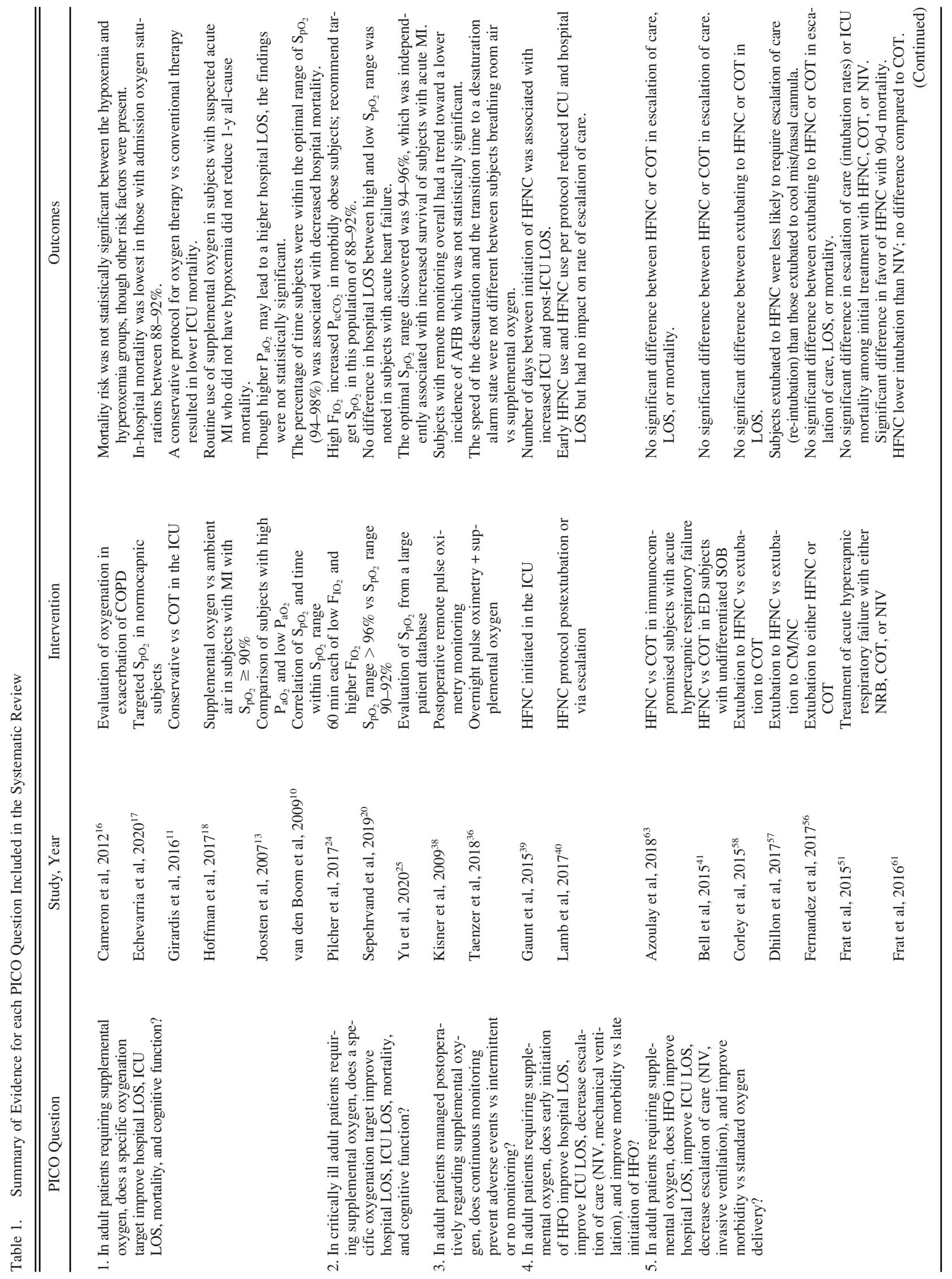




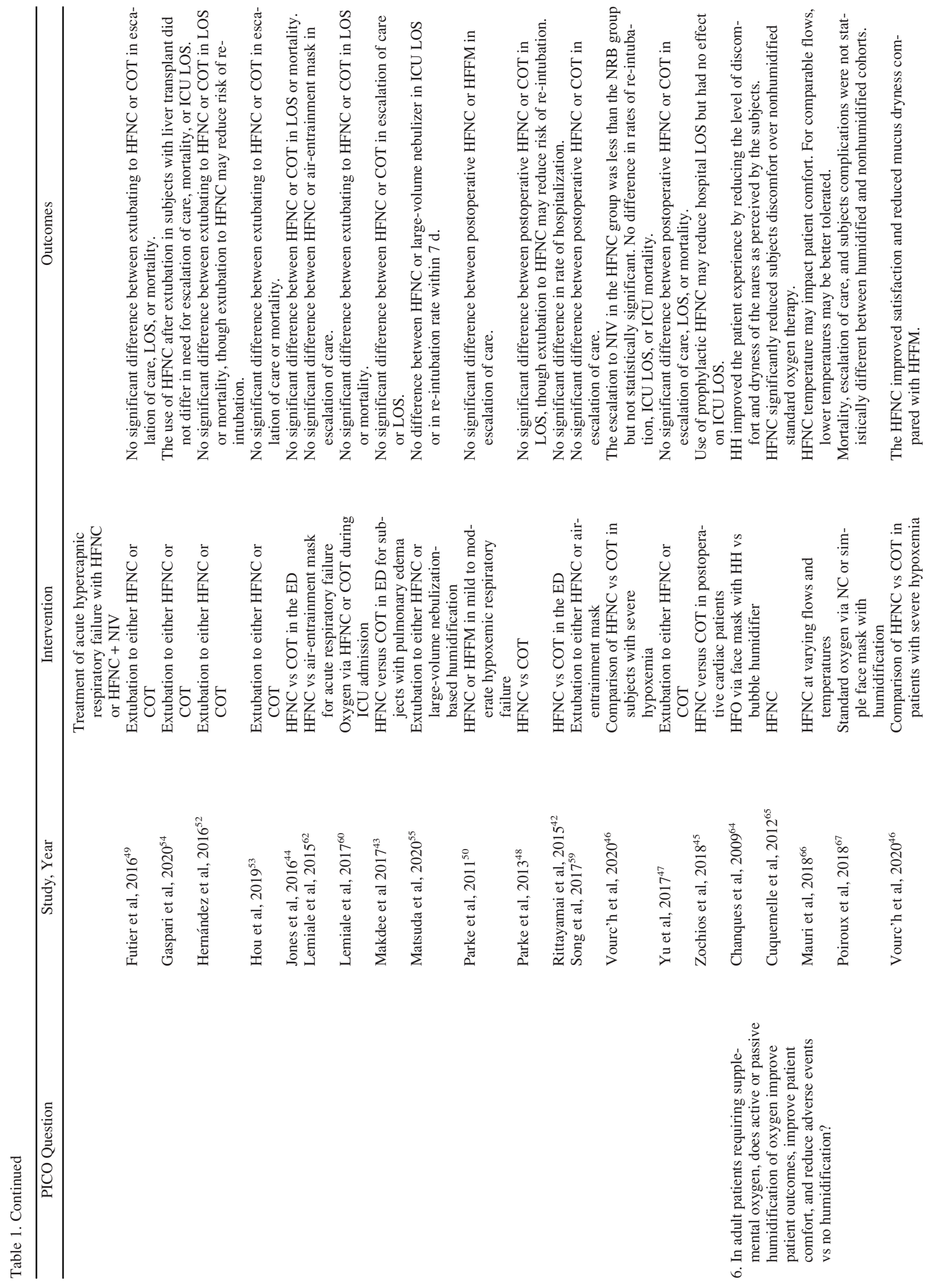




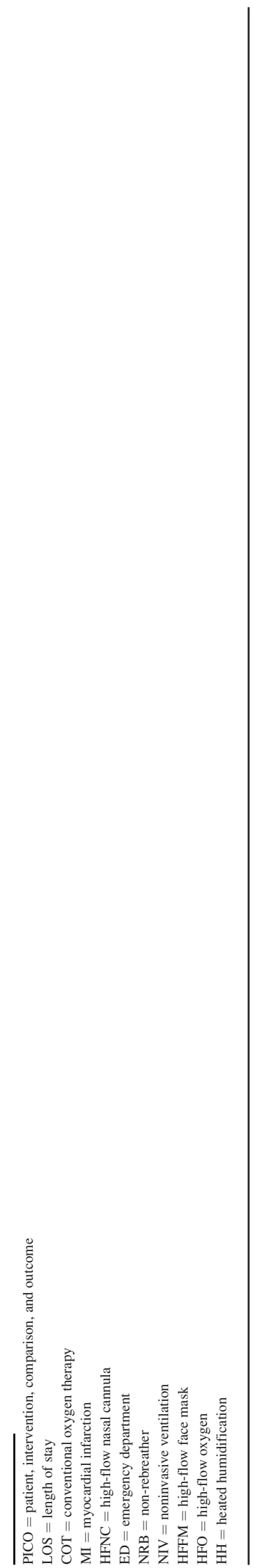

collective experience. To achieve this, a modification of the RAND/UCLA Appropriateness Method ${ }^{9}$ was used. The literature was collapsed into evidence tables according to PICO question (Table 1). Individual panel members were assigned the task of writing a systematic review of the topic, drafting one or more recommendations, and suggesting the level of evidence supporting the recommendation:

A. Convincing scientific evidence based on randomized controlled trials of sufficient rigor;

B. Weaker scientific evidence based on lower levels of evidence such as cohort studies, retrospective studies, case-control studies, and cross-sectional studies;

C. Based on the collective experience of the committee.

Committee members reviewed the first draft of evidence tables, systematic reviews, recommendations, and evidence levels. Each committee member rated each recommendation using a Likert scale of 1 to 9, with 1 meaning expected harms greatly outweigh the expected benefits and 9 meaning expected benefits greatly outweigh the expected harms. The ratings were returned to the committee chair. The first ratings were done with no interaction among committee members. A conference call was convened, during which time the individual committee ratings were discussed. Particular attention was given to any outlier scores and the justification. Recommendations and evidence levels were revised with input from the committee members. After discussing each PICO question, committee members re-rated each recommendation. The final median and range of committee members' scores are reported (Table 2). Strong agreement required that all committee members rank the recommendation 7 or higher; weak agreement meant that one or more committee members ranked the recommendation below 7 , but the median vote was at least 7 . For recommendations with weak agreement, the percentage of committee members who rated 7 or above was calculated and reported after each weak recommendation. Figure 1 illustrates the process flow the panel used to rate the appropriateness and quality of the literature selected through the search process.

Drafts of the report were distributed among committee members in several iterations. When all committee members were satisfied, the document was submitted for publication. The report was subjected to peer review before final publication.

\section{Assessment and Recommendations}

The search strategies retrieved a total of 6,984 articles. After the removal of duplicates, 4,063 articles remained for screening, of which 3,586 were excluded at the title and abstract level. Of the remaining 477 articles, 437 were excluded following full-text review against the inclusion and 


\section{AarC Clinical Practice Guideline: Managing Oxygen in Acute Care}

Table 2. Summary of Recommendations for Each PICO Question

\begin{tabular}{|c|c|}
\hline PICO Question & Summary of Recommendations \\
\hline $\begin{array}{l}\text { In adult patients requiring supplemental oxygen, does a specific } \\
\text { oxygenation target improve hospital LOS, ICU LOS, mortality, and } \\
\text { cognitive function? }\end{array}$ & $\begin{array}{l}\text { The committee supports an optimal } \mathrm{S}_{\mathrm{pO}_{2}} \text { range of } 94-98 \% \text { for most patients } \\
\text { requiring supplemental oxygen, a range of } 88-92 \% \text { for patients with } \\
\text { COPD who require supplemental oxygen, (Evidence level C; all commit- } \\
\text { tee members responded } 7 \text { ). }\end{array}$ \\
\hline $\begin{array}{l}\text { In critically ill adult patients requiring supplemental oxygen, does a } \\
\text { specific oxygenation target improve hospital LOS, ICU LOS, } \\
\text { mortality, and cognitive function? }\end{array}$ & $\begin{array}{l}\text { The committee recommends an } \mathrm{S}_{\mathrm{pO}_{2}} \text { range of } 94-98 \% \text { for critically ill } \\
\text { patients (Evidence level C; all committee members responded 7). }\end{array}$ \\
\hline $\begin{array}{l}\text { In adult patients managed postoperatively regarding supplemental } \\
\text { oxygen, does continuous monitoring prevent adverse events vs } \\
\text { intermittent or no monitoring? }\end{array}$ & $\begin{array}{l}\text { Based on the paucity of literature, there are no recommendations at this } \\
\text { time. }\end{array}$ \\
\hline $\begin{array}{l}\text { In adult patients requiring supplemental oxygen, does early initiation of } \\
\text { HFO improve hospital LOS, improve ICU LOS, decrease } \\
\text { escalation of care (NIV, invasive ventilation), and improve } \\
\text { morbidity vs late initiation of HFO? }\end{array}$ & $\begin{array}{l}\text { The limited available literature and experiences of the committee support early } \\
\text { initiation of HFNC vs late initiation of HFNC based on the clinical condition } \\
\text { of the patient (Evidence level C; median appropriateness score 8, range 7-9). }\end{array}$ \\
\hline $\begin{array}{l}\text { In adult patients requiring supplemental oxygen, does HFO } \\
\text { improve hospital LOS, improve ICU LOS, decrease escalation } \\
\text { of care (NIV, invasive ventilation), and improve morbidity } \\
\text { versus standard oxygen delivery? }\end{array}$ & $\begin{array}{l}\text { Based on the available evidence and the experience of the committee, } \\
\text { HFNC may avoid escalation to NIV and the need for invasive ventilation, } \\
\text { likely due to its effects on oxygenation, and dyspnea compared to COT; } \\
\text { however, HFNC does not reduce LOS compared to COT (Evidence level } \\
\text { B; median appropriateness score 8, range 7-9). Compared to COT, } \\
\text { HFNC appears to reduce re-intubation when used immediately postextu- } \\
\text { bation (Evidence level B; all committee members responded 8).There } \\
\text { appears to be no benefits in LOS, escalation of care, or morbidity of } \\
\text { HFNC compared to COT in immunocompromised patients (Evidence } \\
\text { level B; all committee members responded 8). }\end{array}$ \\
\hline $\begin{array}{l}\text { In adult patients requiring supplemental oxygen, does active or passive } \\
\text { humidification of oxygen improve patient outcomes, improve patient } \\
\text { comfort, and reduce adverse events vs no humidification? }\end{array}$ & $\begin{array}{l}\text { The available evidence and the experience of the committee suggest that humid- } \\
\text { ification may be considered for oxygen flows }>4 \mathrm{~L} / \mathrm{min} \text { to improve patient } \\
\text { comfort (Evidence level C; median appropriateness score } 8 \text {, range 7-9). }\end{array}$ \\
\hline $\begin{array}{l}\text { PICO = patient, intervention, comparison, and outcome } \\
\text { LOS = length of stay } \\
\text { HFO = high-flow oxygen } \\
\text { NIV = noninvasive ventilation } \\
\text { HFNC = high-flow nasal cannula } \\
\text { COT = conventional oxygen therapy }\end{array}$ & \\
\hline
\end{tabular}

exclusion criteria, leaving 40 articles included for synthesis (Fig. 2).

\section{Specific Oxygenation Targets in Acutely Ill Adults}

There is increased attention given to determine safe levels of oxygen therapy in ICUs, emergency departments (ED), and specific diseases. Several studies use $\mathrm{S}_{\mathrm{pO}}$, versus $\mathrm{P}_{\mathrm{aO}}$, to assess oxygenation as $\mathrm{S}_{\mathrm{pO}_{2}}$ is readily available, noninvasive, cost-effective, and easily measured. ${ }^{10,11}$

A large single-center RCT randomized 434 subjects to a conservative oxygen protocol versus a conventional control group. ${ }^{11}$ The conservative group was assigned to receive oxygen therapy to maintain $\mathrm{P}_{\mathrm{aO}_{2}}$ between $70-100 \mathrm{~mm} \mathrm{Hg}$ or $\mathrm{S}_{\mathrm{pO}_{2}}$ between 94-98\%. The conventional group allowed $\mathrm{P}_{\mathrm{aO}_{2}}$ up to $150 \mathrm{~mm} \mathrm{Hg}$ or $\mathrm{P}_{\mathrm{O}_{2}}$ between $97-100 \%$. The median $\mathrm{P}_{\mathrm{aO}}$ values during the ICU LOS were significantly higher $(P<.001)$ in the conventional group (median $\mathrm{P}_{\mathrm{aO}_{2}}$ $102 \mathrm{~mm} \mathrm{Hg}$ [interquartile range [IQR] 88-116]) vs the conservative group (median $\mathrm{P}_{\mathrm{aO}_{2}} 87 \mathrm{~mm} \mathrm{Hg}$ [IQR 79-97]). Mortality rates were lower in the conservative group. The study also reported fewer episodes of shock, liver failure, and bacteremia in the conservative group.

A 2009 retrospective observational study by van den Boom and colleagues ${ }^{10}$ analyzed and compared the $\mathrm{S}_{\mathrm{pO}_{2}}$ of 26,723 records of ICU patients from the eICU Collaborative Research Database and 8,546 records of patients from the Medical Information Mart for Intensive Care III database to hospital mortality rate. The results demonstrated that the optimal range of $\mathrm{S}_{\mathrm{pO}_{2}}$ associated with decreasing mortality was 94-98\%. Conversely, it was also noted that an $\mathrm{S}_{\mathrm{pO}_{2}}<94 \%$ was associated with increased mortality. The authors' results are a reminder of the importance of oxygen 


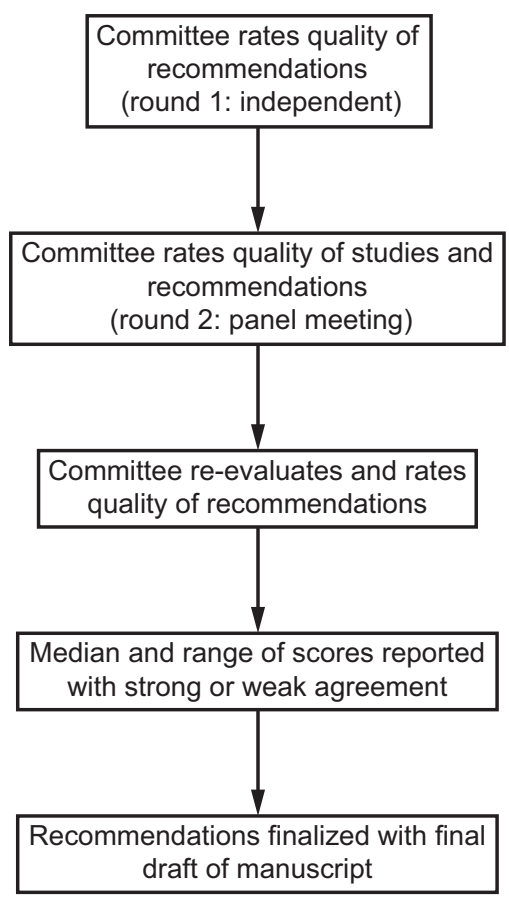

Fig. 1. Process used by the committee to appraise the literature.

therapy in preventing hypoxemia and limiting its usage to prevent hyperoxia.

Raksakietisak et al ${ }^{12}$ studied 2 oxygen therapy devices to prevent hypoxemia. Hypoxemia was defined as an $\mathrm{S}_{\mathrm{pO}_{2}}<$ 94\% and the threshold in which to initiate oxygen therapy. This was an RCT comparing nasal cannula to a simple face mask in 500 low-risk post-anesthesia subjects in the post-anesthesia care unit. The first group received $4 \mathrm{~L} / \mathrm{min}$ of oxygen via nasal cannula, whereas the second group received $5 \mathrm{~L} / \mathrm{min}$ through an oxygen mask. Both methods resulted in a comparable $\mathrm{F}_{\mathrm{IO}_{2}}$ (0.35). There was no significant difference in $\mathrm{S}_{\mathrm{pO}_{2}}$ between the 2 devices. This study concluded that both nasal cannula and a simple face masks can prevent hypoxemia.

Other studies focused on oxygen therapy for specific diseases. High $\mathrm{F}_{\mathrm{IO}_{2}}$ delivered to patients with COPD with hypercapnia in respiratory failure can lead to worsening gas exchange, increased morbidity, and mortality. ${ }^{13,14}$ Studies in this population have recommended administering 2 $\mathrm{L} / \mathrm{min}$ of oxygen or $0.28 \mathrm{~F}_{\mathrm{IO}_{2}}$ to minimize these effects. ${ }^{13-15}$ Joosten et $\mathrm{al}^{13}$ performed a retrospective review of subjects admitted to the ED with a COPD exacerbation. Subjects with $\mathrm{P}_{\mathrm{aCO}}>45 \mathrm{~mm} \mathrm{Hg}$ were considered $\mathrm{CO}_{2}$ retainers. Results demonstrated an increase in LOS, use of NIV, and a higher admission rate to an ICU for persons with COPD who were $\mathrm{CO}_{2}$ retainers and received supplemental $\mathrm{O}_{2}>4$ $\mathrm{L} / \mathrm{min}$. This study emphasizes the importance of managing the amount of oxygen for patients with COPD. Two other studies focused on in-hospital mortality with subjects receiving supplemental oxygen and admitted with COPD

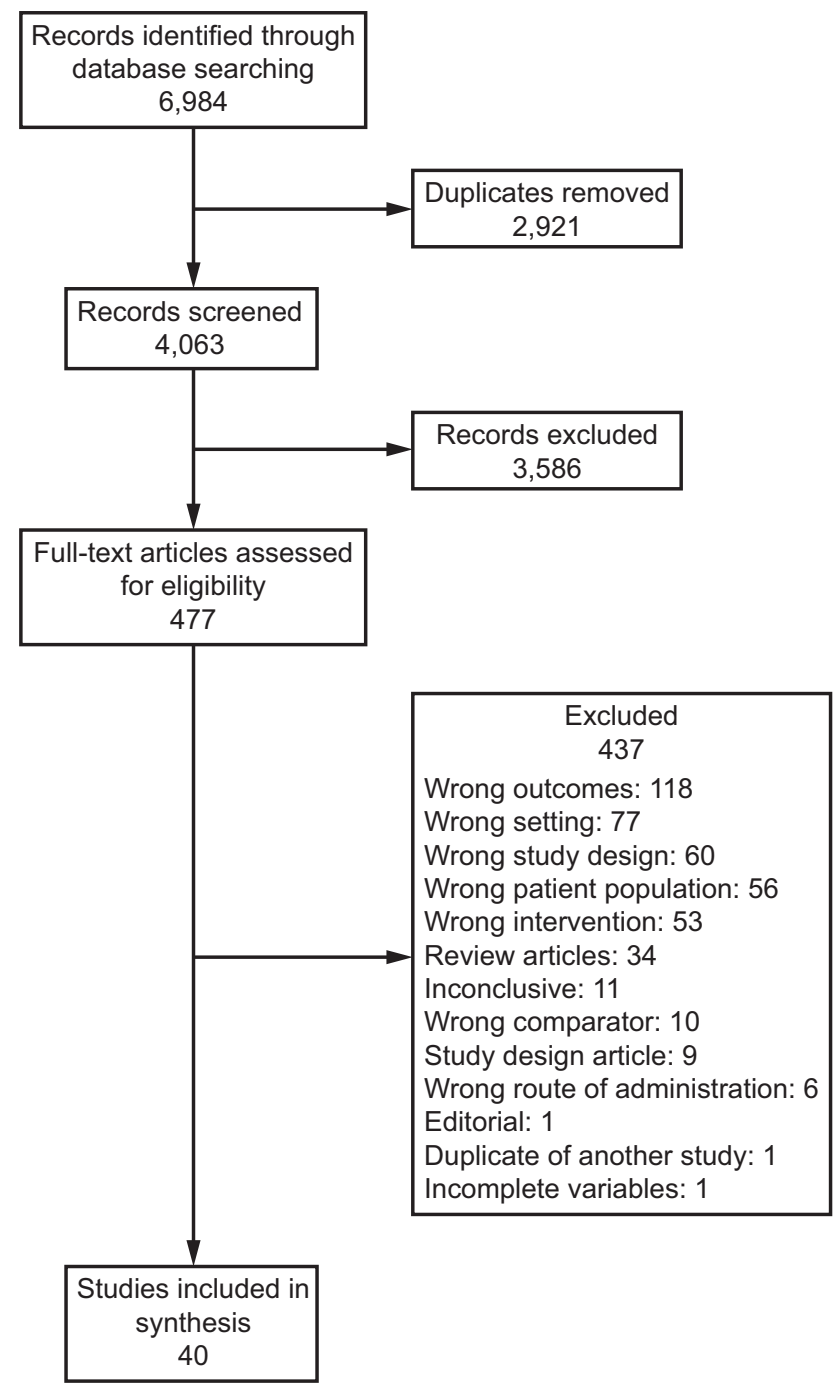

Fig. 2. Flow chart.

exacerbation. Cameron et $\mathrm{al}^{16}$ found an increase in adverse outcomes in this population with $\mathrm{S}_{\mathrm{pO}_{2}}<88 \%$ or $>96 \%$. Echevarria and colleagues ${ }^{17}$ also studied in-hospital mortality with subjects receiving supplemental oxygen and admitted with COPD exacerbation, hypercapnia, and normocapnia. In-hospital mortality was lowest in both groups when targeting oxygen saturation of $88-92 \%$.

Hoffman et $\mathrm{al}^{18}$ conducted an RCT to compare the routine use of oxygen in subjects with an acute myocardial infarction without hypoxemia. A sample of 6,629 subjects $>30$-y old and with an $\mathrm{S}_{\mathrm{pO} 2}>90 \%$ received either supplemental oxygen or ambient air. The authors found no impact on mortality with the routine administration of oxygen at 1-y in subjects with suspected myocardial infarction with no sign of hypoxemia.

Smit and colleagues ${ }^{19}$ evaluated the use of oxygen therapy following coronary artery bypass graft (CABG) surgery in an RCT of 50 subjects to either a moderate hyperoxia 
Table 3. Recommended $\mathrm{S}_{\mathrm{pO}_{2}}$ Range by Population

\begin{tabular}{lrr}
\hline \hline & $\mathrm{S}_{\mathrm{pO}_{2}}$ Range & $\mathrm{P}_{\mathrm{aO}_{2}}$ Range \\
\hline Patients requiring oxygen & $94-98 \%$ & $70-100 \mathrm{~mm} \mathrm{Hg}$ \\
Patients with COPD requiring oxygen & $88-92 \%$ & $55-75 \mathrm{~mm} \mathrm{Hg}$ \\
Patients requiring $\mathrm{F}_{\mathrm{IO}_{2}} \geq 0.70 *$ & $88-93 \% *$ & $55-80 \mathrm{~mm} \mathrm{Hg}$ \\
& & \\
*A higher PEEP strategy may reduce the negative effects of high $\mathrm{F}_{\mathrm{IO}_{2}}$ on functional residual \\
capacity during mechanical ventilation if tolerated and safe.
\end{tabular}

state or a near-physiologic oxygen state. The results demonstrated no decrease in myocardial damage to the $\mathrm{CABG}$ with a near-physiological oxygen strategy. There were no increases in lactate levels or hypoxic events.

The available literature and experiences of the committee support using $\mathrm{S}_{\mathrm{pO}_{2}}$ to monitor oxygenation to prevent hypoxemia and hyperoxia to decrease mortality. The literature also suggests that there is no benefit to hyperoxia and rather supports the importance of maintaining normoxia among patients with myocardial infarction and CABG. Therefore, the committee supports an optimal $\mathrm{S}_{\mathrm{pO}_{2}}$ range of $94-98 \%$ for most patients requiring supplemental oxygen and a range of 88-92\% for patients with COPD who require supplemental oxygen. Finally, it is important to manage the oxygen given to an exacerbation of COPD that is a $\mathrm{CO}_{2}$ retainer (Table 3) (Evidence level C; all committee members responded 7).

\section{Specific Oxygenation Targets in Critically Ill Adults}

The harmful effects of hyperoxemia have been debated for decades. ${ }^{20,21}$ Protocols designed to limit hyperoxemia have become more common in intensive care. ${ }^{22}$ Although the contributive effects of conservative oxygenation goals are not fully understood, several studies aimed to identify positive outcomes. ${ }^{1,11,22,23}$ It has been hypothesized that maintaining $\mathrm{S}_{\mathrm{pO}_{2}}$ within specific parameters negatively impacts patients with ventilatory failure. ${ }^{24}$ Whereas several studies have used oxygen targets to titrate $\mathrm{F}_{\mathrm{IO}_{2}}$ in mechanically ventilated patients, there is a dearth of data available in patients requiring supplemental oxygen.

In a crossover RCT, Pilcher and colleagues ${ }^{24}$ reported that high concentrations of oxygen positively correlated with increased $\mathrm{P}_{\mathrm{aCO}}$ in morbidly obese subjects. Subjects with a body mass index $>40 \mathrm{~kg} / \mathrm{m}^{2}$ were placed on 8 $\mathrm{L} / \mathrm{min}$ face masks $(n=12)$ and compared with those placed on low-flow oxygen $(n=12)$. Subjects exposed to higher oxygen concentration were more likely to have higher transpulmonary $\mathrm{P}_{\mathrm{CO}_{2}}\left(\mathrm{P}_{\mathrm{tcCO}_{2}}\right)$ than those on low-flow oxygen (outcome difference 3.2 [1.3-5.2], $P=.002$ ). The authors' main finding was that high-concentration oxygen therapy increased $\mathrm{P}_{\mathrm{tcCO}}$ in morbidly obese in-patients to a significantly greater degree than titrating oxygen to achieve a target $\mathrm{S}_{\mathrm{pO}_{2}}$ of $88-92 \%$.
Sepehrvand et $\mathrm{al}^{20}$ studied oxygen titration to maintain either high $\left(\mathrm{S}_{\mathrm{pO}_{2}} \geq 96 \%\right)$ or low $\left(\mathrm{S}_{\mathrm{pO}_{2}} 90-92 \%\right)$ oxygen saturation range in subjects admitted for acute heart failure. Hospital LOS was significantly higher in the low $\mathrm{S}_{\mathrm{pO}_{2}}$ group (9.5 d vs $4.7 \mathrm{~d}, P=.01$ ). However, when the population was adjusted for age, sex, residence times, and prior medical history (including cardiac devices), no difference was found $(P=.07)$. Overall, no differences were found between groups when oxygen was adjusted to meet targets in the first $72 \mathrm{~h}$ after admission. In a retrospective analysis of the association between admission $\mathrm{S}_{\mathrm{pO}_{2}}$ and all-cause in-hospital mortality, $\mathrm{Yu}$ and colleagues ${ }^{25}$ found that the optimal range for $\mathrm{S}_{\mathrm{pO}_{2}}$ for subjects with acute myocardial infarction was 94-96\%.

Guidance from the ARDSNet studies includes a recommended safe oxygenation range of $88-95 \%\left(\mathrm{P}_{\mathrm{a}} \mathrm{O}_{2}, 55-80\right.$ $\mathrm{mm} \mathrm{Hg}$ ) for patients with severe acute hypoxemia. In a 2021 study, Schjørring et $\mathrm{al}^{26}$ found no difference in mortality when targeting $\mathrm{P}_{\mathrm{aO}_{2}} 60 \mathrm{~mm} \mathrm{Hg}$ versus $90 \mathrm{~mm} \mathrm{Hg}$ $\left(\mathrm{S}_{\mathrm{pO}_{2}}\right.$ 90-97\%). Although the authors did not address $\mathrm{P}_{\mathrm{aO}}$ $<60 \mathrm{~mm} \mathrm{Hg}$ or $>90 \mathrm{~mm} \mathrm{Hg}$, it is reasonable to consider an oxygenation range of $90-97 \%$ as safe.

Despite no difference found in mortality for patients with low or high $\mathrm{P}_{\mathrm{aO}}$, patients with severe ARDS may require high levels of $\mathrm{F}_{\mathrm{IO}_{2}}$ to maintain acceptable oxygenation. In preclinical animal data, high levels of $\mathrm{F}_{\mathrm{IO}_{2}}$ delivered for prolonged periods of time have consistently shown to contribute to oxidative injury. ${ }^{27}$ Furthermore, studies in both adults and pediatric patients receiving invasive mechanical ventilation have shown a reduction in functional residual capacity that occurs due to de-nitrogenation atelectasis. ${ }^{28}$ However, these effects may be mitigated if a high PEEP strategy can be utilized safely. ${ }^{28}$ Many randomized trials of mechanical ventilation for ARDS have utilized an oxygenation target saturation of $88-93 \%$ to facilitate the use of the lowest possible $\mathrm{F}_{\mathrm{IO}_{2}} \cdot{ }^{29-31}$

The available evidence is weak to suggest that titration of oxygen saturation improves outcomes such as mortality and hospital LOS in critically ill adults. It is unknown whether the scant amount of available literature can be generalized to wider populations. Despite these findings, the committee recommends an $\mathrm{S}_{\mathrm{pO}_{2}}$ range of $94-98 \%$ for critically ill patients. However, based on previous ARDS studies and the experience of the committee, an oxygen saturation target of 88-93\% should be used when critically ill patients require $\mathrm{F}_{\mathrm{IO}_{2}}$ of 0.70 or higher to maintain oxygen, particularly when they are not undergoing invasive ventilation with a high PEEP strategy (Evidence level C; all committee members responded 7).

\section{Postoperative Continuous Monitoring}

Monitoring the postoperative hospitalized patient with noninvasive monitoring, such as a pulse oximeter or capnography, has been suggested to detect respiratory depression and 


\section{AarC Clinical Practice Guideline: Managing Oxygen in Acute Care}

prevent adverse events, including death. ${ }^{32-34}$ Continuous monitoring via pulse oximetry and/or capnography may provide earlier detection of these abnormalities but may also contribute to the cacophony of alarms that lead to alarm fatigue. ${ }^{35}$

In response to concerns about pulse oximetry allowing detection of deterioration early enough for intervention in patients receiving supplemental oxygen, Taenzer et $\mathrm{al}^{36}$ studied the rate of desaturation in subjects receiving supplemental oxygen versus those not receiving supplemental oxygen. They reported that the speed of desaturation was not different between the groups, concluding that pulse oximetry-based surveillance can be used in the patient receiving supplemental oxygen to detect deterioration.

A 2017 systematic review by Lam et $\mathrm{al}^{37}$ focused on the effectiveness of continuous pulse oximetry versus routine care and the effectiveness of continuous capnography with or without pulse oximetry in the postoperative population, though not all studies included in the review included supplemental oxygen delivery. Routine care was defined as vital signs obtained every 4-6 h. They identified 4 studies comparing continuous pulse oximetry to routine care and found that the odds of recognizing desaturation were significantly higher with continuous pulse oximetry versus routine care. In addition, they identified 5 studies evaluating the use of capnography with or without pulse oximetry. Those studies revealed that the odds of recognizing postoperative respiratory distress were significantly higher using capnography than with the use of pulse oximetry.

Kisner et $\mathrm{al}^{38}$ studied the incidence of cardiac arrhythmias identified postoperatively via remote pulse oximetry monitoring versus no monitoring in subjects that required CABG or cardiac valve replacements. They found that subjects who were monitored had a lower incidence of atrial fibrillation than those who were not monitored, although this did not reach statistical significance.

Though there is evidence to support the use of monitoring via pulse oximetry and capnography to prevent postoperative respiratory distress, there is a paucity of evidence comparing continuous monitoring to intermittent or no monitoring in patients receiving supplemental oxygen, including impact on mortality. At this time, no recommendation can be made.

\section{Early Initiation of High-Flow Nasal Cannula}

Early initiation of HFNC is not clearly defined in the literature. For this review, the committee included studies that explored the impact of time to initiation of HFNC and those studying HFNC applied postextubation to prevent or reverse postextubation respiratory failure. Even with these qualifiers, there is a paucity of literature exploring the timing of initiating HFNC or comparing early versus late initiation.
Gaunt et $\mathrm{al}^{39}$ in a retrospective study identified the timing of initiation of HFNC and the occurrence of adverse events, ICU LOS, and post-ICU LOS. They found that the number of days to the initiation of HFNC was associated with an increased post-ICU LOS $(P=.003)$ and the number of days between admission to the ICU and initiation of HFNC was associated with an increased ICU LOS $(P<.001)$. The timing of the initiation of HFNC was not significantly related to escalation of care $(P=.06)$.

In a prospective evaluation, Lamb et $\mathrm{al}^{40}$ studied extubation directly to HFNC or HFNC after extubation only if oxygen requirements escalated to $4 \mathrm{~L} / \mathrm{min}$ via standard nasal oxygen. Both groups had a control group from a retrospective analysis in the pre-study period. In the group extubated directly to HFNC, neither hospital LOS nor ICU LOS differed significantly between the study and control groups ( $P=.27$ and $P=.79$, respectively), nor did the study group differ in need for re-intubation $(P=.99)$. However, in the other group, they identified that, when used early, hospital and ICU LOS were reduced $(P=.007$ and $P=.03$, respectively).

The limited available evidence and experience of the committee support early initiation of HFNC versus late initiation of HFNC based on the clinical condition of the patient (Evidence level C; median appropriateness score 8, range 7-9).

\section{High-Flow Nasal Cannula Versus Standard Oxygen}

Several studies compared HFNC to conventional oxygen therapy. Many of these studies can be placed into the following categories of patient areas: ED, postoperative care, ICU, and postextubation. Additionally, several studies assessed HFNC in subjects with immunosuppression. Each of these areas, and studies of immunosuppression, will be presented separately for the effects of HFNC compared to conventional oxygen therapy on ICU and hospital LOS, escalation of care (to NIV and intubation), and morbidity.

Studies included in this analysis that compared conventional oxygen therapy to early initiation of HFNC in the ED

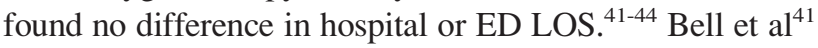
found a significant reduction in breathing frequency $(6.7 \%$ vs $38.5 \%, P=.005)$ and escalation of care $(4.2 \%$ vs $19.0 \%, P=.02)$ and improvements in dyspnea. A reduction in breathing frequency was also found in other studies conducted in the ED. ${ }^{42,43}$ Jones et $\mathrm{al}^{44}$ assessed the impact of HFNC treatment in the ED, including mortality, and found no difference between subjects treated with conventional oxygen therapy.

Several studies assessed the impact of HFNC after surgery when supplemental oxygen was required. ${ }^{45-49}$ Hospital and ICU LOS were not significantly different in most of the included studies. However, Zochios et $\mathrm{al}^{45}$ found significantly lower hospital $\operatorname{LOS}(P=.01)$ and significantly fewer 
ICU readmissions $(P=.03)$ in subjects treated with HFNC prophylactically after cardiac surgery compared to conventional oxygen therapy. Vourc'h et $\mathrm{al}^{46}$ found less need for escalation to NIV in subjects treated with HFNC after cardiac surgery $(P=.007)$. Yu et al ${ }^{47}$ also reported less escalation to NIV $(P=.01)$ and fewer reintubations $(P=.031)$ using HFNC compared to conventional oxygen therapy in subjects treated with HFNC after thoracic surgery. Improved oxygenation and less dyspnea likely led to less perceived respiratory distress and, therefore, less escalation of care. In postoperative studies that assessed mortality as an outcome, no difference was found between subjects treated with HFNC compared to conventional oxygen therapy.

Few randomized trials compared HFNC to conventional oxygen therapy in subjects meeting criteria of respiratory failure admitted to the ICU (separate from the ED discussed above or subjects with immunosuppression discussed later) ${ }^{50,51}$ None of the studies found a significant difference in hospital or ICU LOS. Parke et $\mathrm{al}^{50}$ reported higher success of therapy with HFNC compared to face mask $(P=$ $.006)$, with significantly fewer desaturation episodes $(P=$ .009). However, no difference was found in the rate of intubation. Frat et $\mathrm{al}^{51}$ assessed rate of intubation as the primary outcome and found no difference overall between subjects treated with HFNC compared to conventional oxygen therapy. However, in a post hoc analysis, they found lower intubation rates in subjects with $\mathrm{P}_{\mathrm{aO}_{2}} / \mathrm{F}_{\mathrm{IO}_{2}} \leq 200 \mathrm{~mm} \mathrm{Hg}$. This 2015 research was the only study reporting a lower $90-\mathrm{d}$ mortality for subjects treated with HFNC compared to conventional oxygen therapy and NIV. This finding of lower mortality was likely influenced by the reduction in intubation found in subjects with more severe hypoxemia.

Assessment of the use of HFNC compared to conventional oxygen therapy immediately after extubation was the objective of several RCTs. ${ }^{52-59}$ Hospital and ICU LOS were not different. Hernández et $\mathrm{al}^{52}$ found lower re-intubation within $72 \mathrm{~h}$ of extubation using HFNC compared to conventional oxygen therapy in subjects at low risk of extubation failure $(P=.004)$. Hou et $\mathrm{al}^{53}$ found less escalation to NIV $(P=$ $.02)$ and lower re-intubation $(P=.036)$ using HFNC compared to an air-entrainment mask. However, neither Gaspari et $\mathrm{al}^{54}$ nor Matsuda et $\mathrm{al}^{55}$ found a difference in escalation of care or ICU LOS when they compared HFNC with a heated humidified face mask, suggesting perhaps that humidification plays an important role. No difference was found in mortality using HFNC or conventional oxygen therapy. ${ }^{53,56}$

A total of 4 studies were included in our analysis that compared HFNC with conventional oxygen therapy in a specific patient population of immunosuppression. ${ }^{60-63}$ Two of the studies were post hoc analysis of previous RCTs ${ }^{60,61}$ and 2 were prospective RCTs. ${ }^{62,63}$ No difference was found using HFNC compared to conventional oxygen therapy for hospital or ICU LOS, escalation of care, or mortality. Frat et $\mathrm{al}^{61}$ found lower 90 -d mortality using HFNC compared to NIV in their analysis $(P=.02)$ but no difference compared to conventional oxygen therapy $(P=.65)$.

Based on the available evidence and the experience of the committee, HFNC may avoid escalation to NIV and the need for intubation in patients with significant hypoxemia, likely due to its effects on oxygenation and dyspnea compared to conventional oxygen therapy. However, HFNC does not reduce LOS compared to conventional oxygen therapy. Further evidence is required to confirm a mortality benefit using HFNC compared to conventional oxygen therapy (Evidence level B; median appropriateness score 8, range 7-9).

Compared to conventional oxygen therapy, HFNC reduces re-intubation when used immediately postextubation (Evidence level B; all committee members responded 8).

There are no benefits in LOS, escalation of care, or morbidity of HFNC compared to conventional oxygen therapy in immunocompromised patients (Evidence level B; all committee members responded 8).

\section{Humidification of Oxygen}

There is a lack of high-level evidence to support an impact of humidity on patient outcomes or adverse events. Most evidence centers on patient comfort. In a prospective crossover study, Chanques et $\mathrm{al}^{64}$ compared the comfort level associated with high-flow face mask with bubble humidification versus high-flow face mask with heated humidification $(\mathrm{HH})$. Subjects indicated that, when $\mathrm{HH}$ was used, they had less discomfort. As compared to bubble humidification, the oxygen delivery system using $\mathrm{HH}$ scored more favorably on the dryness scale and was preferred by subjects.

The only study $(N=30)$ that measured nasal airway caliber (cross-sectional area by acoustic rhinometry) failed to document a difference between HFNC and conventional oxygen therapy. A blinded evaluation by an otorhinolaryngologist demonstrated significantly greater nasal dryness in the standard oxygen group. Subjects' assessment of nasal dryness was judged better with HFNC. Dryness of the mouth and throat, dysphagia, and throat pain was not significantly different between the HFNC and conventional oxygen therapy. Subjects noted a significant overall subjective preference of HFNC over conventional oxygen despite relative noise induced by the device. ${ }^{65}$

Vourc'h et $\mathrm{al}^{46}$ randomized adult subjects with severe hypoxemia after cardiac surgery to either HFNC at 45 $\mathrm{L} / \mathrm{min}$ or non-rebreathing mask at $15 \mathrm{~L} / \mathrm{min}$. They studied self-reported subject satisfaction, mucus dryness, and nasal bleeding. The HFNC cohort experienced more satisfaction $(P<.001)$, less mucus dryness $(P=.003)$, and fewer instances of nasal bleeding $(P=.36)$. 


\section{AarC Clinical Practice Guideline: Managing Oxygen in Acute Care}

The heated nature of the humidification used with HFNC allows the patient to tolerate higher flows. However, the temperature of the device is variable. Mauri et $\mathrm{al}^{66}$ studied the effect of temperature on patient comfort with HFNC. Using 2 flows $(30 \mathrm{~L} / \mathrm{min}$ and $60 \mathrm{~L} / \mathrm{min})$ at 2 temperatures $\left(31^{\circ} \mathrm{C}\right.$ and $\left.37^{\circ} \mathrm{C}\right)$, they studied patient comfort. Their study revealed a higher comfort rate at a lower temperature, regardless of flow.

Even given the above evidence, studies have not been able to determine that nonhumidified supplemental oxygen is inferior to humidified supplemental oxygen. Poiroux et $\mathrm{al}^{67}$ studied humidified and nonhumidified oxygen delivered via nasal cannula at various flows. They reported that nonhumidified oxygen at flows $>4 \mathrm{~L} / \mathrm{min}$ may be associated with higher levels of discomfort but, overall, oxygen therapy-related discomfort was low. They also assessed the effects of oxygen humidification and outcomes such as the incidence of intubation, NIV, ICU LOS, and mortality. They found no significant difference between the outcomes of the humidified and nonhumidified cohorts. They also found no significant difference in the incidence of ear, nose, or throat infection or in the need for bronchoscopy between the 2 groups.

The available evidence and the experience of the committee suggest that humidification may be considered for oxygen flows $>4 \mathrm{~L} / \mathrm{min}$ to improve patient comfort (Evidence level C; median appropriateness score 8, range 7-9).

\section{Summary}

Providing supplemental oxygen to patients in a critical care environment is essential to the management of hypoxemia. Drug delivery of any kind requires thoughtful and evidence-based recommendations regarding how the appropriate dose should be given, and if alternative delivery methods exist, the benefits associated with them should be determined. In this review, we evaluated the available evidence regarding 6 specific PICO questions related to oxygenation targets (dosing), continuous monitoring in the postoperative setting, the increasingly common delivery method of HFNC, and humidification of supplemental oxygen. For the PICO outcomes, the committee agreed to focus on the clinically-relevant patient outcomes of LOS (hospital and ICU) and improved morbidity.

The available evidence was evaluated for the appropriate clinical targets of oxygen saturation for both acutely ill and critically ill adult patients. For acutely ill adult patients, van den Boom et $\mathrm{al}^{10}$ found an optimal $\mathrm{S}_{\mathrm{pO}_{2}}$ target of $94-98 \%$. However, the available data do not uniformly support a specific oxygen saturation target. The use of pulse oximetry should be used to maintain normoxemia. Additionally, there was no benefit found for hyperoxemia in subjects with myocardial infarction and post CABG. ${ }^{18,19}$ High-quality evidence was reported in a 2018 systematic review and meta-analysis. Chu et $\mathrm{al}^{1}$ found that liberal oxygen targets led to higher 30d mortality across 25 RCTs including 16,000 subjects. Median $\mathrm{S}_{\mathrm{pO}_{2}}$ in these trials was $96 \%$ among subjects in the liberal oxygen group. The relative risk of in-hospital mortality increased as oxygen targets were liberalized, although there were no differences found in other morbidities. Patients with $\mathrm{COPD}$ exacerbation and $\mathrm{CO}_{2}$ retention require a more individualized approach for target oxygenation. Patients with ARDS that require $\mathrm{F}_{\mathrm{IO}_{2}}$ of 0.70 or more are at a higher risk of de-nitrogenation atelectasis. Therefore, based on our collective clinical experience, and despite the low-level evidence in the current literature review, the committee recommends $\mathrm{S}_{\mathrm{pO}_{2}}$ 94-98\% for acutely and critically ill adults, $88-92 \%$ for critically ill adults with $\mathrm{CO}_{2}$ retention and/or COPD, and 88-93\% for critically ill patients requiring $\mathrm{F}_{\mathrm{IO}_{2}}$ of 0.70 or higher who are not invasively ventilated with a high PEEP strategy.

Postoperative complications are a clinically relevant concern, and patient monitoring plays a significant role. Due to the limited data comparing continuous monitoring with intermittent monitoring, the committee was unable to provide a recommendation for continuous oxygen saturation monitoring. There is growing evidence supporting the use of capnography, but this practice was not evaluated as part of the PICO question. For these reasons, the committee has no recommendations related to capnography.

Early versus late initiation of HFNC was defined as studies that compared HFNC initiation early rather than later (as escalation of therapy) in their clinical course. The committee found only 2 studies meeting these criteria, and results suggest that earlier application of HFNC may reduce ICU and hospital LOS. However, the evidence available is low quality due to a lack of randomized controlled trials.

There have been several studies published comparing HFNC to conventional oxygen therapy for the treatment of respiratory failure. The available evidence suggests treatment of hypoxemic respiratory failure with HFNC may avoid escalation to NIV and reduce the need for intubation in patients particularly with $\mathrm{P}_{\mathrm{aO}} / \mathrm{F}_{\mathrm{IO}_{2}} \leq 200 \mathrm{~mm} \mathrm{Hg}$ and immediately postextubation when compared to conventional oxygen therapy. Our findings are consistent with a published systematic review and meta-analysis ${ }^{8}$ and subsequent clinical practice guidelines by Rochwerg et al. ${ }^{68}$ These clinical practice guidelines gave a strong recommendation for HFNC over conventional oxygen therapy for hypoxemic respiratory failure, and a conditional recommendation for use immediately postextubation, and postoperatively in cardiac and/or thoracic surgery patients. Further data are required to demonstrate mortality benefits or confirm benefits in ICU or hospital LOS with HFNC compared to conventional oxygen therapy in any patient population.

Though the evidence does not demonstrate a clinical benefit to adding humidification to oxygen therapy, studies have 


\section{AarC Clinical Practice Guideline: Managing Oxygen in Acute Care}

demonstrated that additional humidification does improve patient comfort. Though some sources cite conflicting information about the superiority of HFNC over conventional oxygen therapy with patient comfort and nasal dryness, ${ }^{69}$ this systematic review identified that adding humidification to delivered supplemental oxygen may not improve patient outcomes but could improve tolerability of the device. ${ }^{46,64-66}$ Considering the relative level of discomfort experienced by the patient during their hospitalization, adding humidification to reduce discomfort associated with supplemental oxygen flows $>4 \mathrm{~L} / \mathrm{min}$ is a small concession and easily accomplished.

For several of the research questions in this systematic review, supporting literature focused on the identified outcomes was sparse. The most studied area of interest during the development of this guideline was focused on HFNC. Based on the volume of research published related to HFNC, the committee acknowledges that the quality of evidence related to HFNC is likely to strengthen recommendations for or against its use in certain clinical contexts over the coming years. We are confident that these recommendations for HFNC are consistent with recently published systematic reviews and meta-analyses and clinical practice guidelines and can positively impact patient outcomes. However, there is also a need for more rigorously designed studies to guide clinical decision-making in other areas of oxygen delivery in the acute care setting.

\section{ACKNOWLEDGEMENTS}

The authors would like to thank Ms Shawna Murray for her contribution to the development of the research questions and literature review.

\section{REFERENCES}

1. Chu DK, Kim LHY, Young PJ, Zamiri N, Almenawer SA, Jaeschke $\mathrm{R}$, et al. Mortality and morbidity in acutely ill adults treated with liberal versus conservative oxygen therapy (IOTA): a systematic review and meta-analysis. Lancet 2018;391(10131):1693-1705.

2. Gilbert-Kawai ET, Mitchell K, Martin D, Carlisle J, Grocott MPW. Permissive hypoxemia versus normoxemia for mechanically ventilated critically ill patients. Cochrane Database Syst Rev 2014;2014(5): CD009931.

3. Leeies M, Flynn E, Turgeon A, Paunovic B, Loewen H, Rabbani R, et al. High-flow oxygen via nasal cannula in patients with acute hypoxemic respiratory failure: a systematic review and meta-analysis. Syst Rev 2017;6(1):202.

4. Ni YN, Luo J, Yu H, Liu D, Liang BM, Yao R, Liang ZA. Can highflow nasal cannula reduce the rate of reintubation in adult patients after extubation? A meta-analysis. BMC Pulm Med 2017;17(1):142.

5. Sklar MC, Mohammed A, Orchanian-Cheff A, Del Sorbo L, Mehta S, Munshi L. The impact of high-flow nasal oxygen in the immunocompromised critically ill: a systematic review and meta-analysis. Respir Care 2018;63(12):1555-1566.

6. Huang HW, Sun XM, Shi ZH, Chen GQ, Chen L, Friedrich JO, Zhou JX. Effect of high-flow nasal cannula oxygen therapy versus conventional oxygen therapy and noninvasive ventilation on reintubation rate in adult patients after extubation: a systematic review and meta-analysis of randomized controlled trials. J Intensive Care Med 2018;33(11):609-623.

7. Beng Leong L, Ming WN, Feng LW. High-flow nasal cannula oxygen versus noninvasive ventilation in adult acute respiratory failure: a systematic review of randomized controlled trials. Eur $\mathrm{J}$ Emerg Med 2019;26(1):9-18.

8. Rochwerg B, Granton D, Wang DX, Helviz Y, Einav S, Frat JP, et al. High-flow nasal cannula compared with conventional oxygen therapy for acute hypoxemic respiratory failure: a systematic review and metaanalysis. Intensive Care Med 2019;45(5):563-572.

9. Fitch K, Bernstein SJ, Aguilar MD, Burnand B, LaCalle JR, Lazaro P, et al. The RAND/UCLA Appropriateness Method User's Manual. RAND; 2001.

10. van den Boom W, Hoy M, Sankaran J, Liu M, Chahed H, Feng M, See $\mathrm{KC}$. The search for optimal oxygen saturation targets in critically ill patients: observational data from large ICU databases. Chest 2020;157 (3):566-573.

11. Girardis M, Busani S, Damiani E, Donati A, Rinaldi L, Marudi A, et al. Effect of conservative versus conventional oxygen therapy on mortality among patients in an intensive care unit: the oxygen-ICU randomized clinical trial. JAMA 2016;316(15):1583-1589.

12. Raksakietisak M, Umpornchote H, Chumpathong S, Siriussawakul A, Napachote T, Ladda P, Paongchan S. The efficacy of 2 oxygen therapy devices (nasal cannula vs simple mask) for preventing hypoxemia after general anesthesia: a randomized controlled noninferiority trial of 500 patients. J Med Assoc Thai 2016;99(5):469-476.

13. Joosten SA, Koh MS, Bu X, Smallwood D, Irving LB. The effects of oxygen therapy in patients presenting to an emergency department with exacerbation of chronic obstructive pulmonary disease. Med J Aust 2007;186(5):235-238.

14. Brill SE, Wedzicha JA. Oxygen therapy in acute exacerbations of chronic obstructive pulmonary disease. Int J Chron Obstruct Pulmon Dis 2014;9:1241-1252.

15. McKenzie DK, Frith PA, Burdon JGW, Town GI; Thoracic Society of Australia and New Zealand. The COPDX plan: Australian and New Zealand guidelines for the management of chronic obstructive pulmonary disease 2003. Med J Aust 2003;178(S6):S1-S40.

16. Cameron L, Pilcher J, Weatherall M, Beasley R, Perrin K. The risk of serious adverse outcomes associated with hypoxemia and hyperoxemia in acute exacerbations of COPD. Postgrad Med J 2012;88 (1046):684-689

17. Echevarria C, Steer J, Wason J, Bourke S. Oxygen therapy and inpatient mortality in COPD exacerbation. Emerg Med J 2021;38 (3): 170-177.

18. Hofmann R, James SK, Jernberg T, Lindahl B, Erlinge D, Witt N, et al; DETO2X-SWEDEHEART Investigators. Oxygen therapy in suspected acute myocardial infarction. N Engl J Med 2017;377 (13):1240-1249.

19. Smit B, Smulders YM, de Waard MC, Boer C, Vonk ABA, Veerhoek $\mathrm{D}$, et al. Moderate hyperoxic versus near-physiological oxygen targets during and after coronary artery bypass surgery: a randomized controlled trial. Crit Care 2016;20(1):55.

20. Sepehrvand N, Alemayehu W, Rowe BH, McAlister FA, van Diepen S, Stickland M, Ezekowitz JA. High versus low oxygen therapy in patients with acute heart failure: HiLo-HF pilot trial. ESC Heart Fail 2019;6(4):667-677.

21. Kallet RH, Matthay MA. Hyperoxic acute lung injury. Respir Care 2013;58(1):123-141.

22. Helmerhorst HJ, Schultz MJ, van der Voort PH, Bosman RJ, Juffermans NP, deWilde RB, et al. Effectiveness and clinical outcomes of a 2-step implementation of conservative oxygenation targets 


\section{AarC Clinical Practice Guideline: Managing Oxygen in Acute Care}

in critically ill patients: a before and after trial. Crit Care Med 2016;44 (3):554-563.

23. Helmerhorst HJ, Roos-Blom MJ, van Westerloo DJ, de Jonge E. Association between arterial hyperoxia and outcome in subsets of critical illness: a systematic review, meta-analysis, and meta-regression of cohort studies. Crit Care Med 2015;43(7):1508-1519.

24. Pilcher J, Richards M, Eastlake L, McKinstry SJ, Bardsley G, Jefferies S, et al. High-flow or titrated oxygen for obese medical inpatients: a randomized crossover trial. Med J Aust 2017;207(10):430-434.

25. Yu Y, Wang J, Wang Q, Wang J, Min J, Wang S, et al. Admission oxygen saturation and all-cause in-hospital mortality in acute myocardial infarction patients: data from the MIMIC-III database. Ann Transl Med 2020;8(21):1371-1371.

26. Schjørring OL, Klitgaard TL, Perner A, Wetterslev J, Lange T, Siegemund M, et al; HOT-ICU Investigators. Lower or higher oxygen targets for acute hypoxemic respiratory failure. $\mathrm{N}$ Engl $\mathrm{J}$ Med 2021;384(14):1301-1311.

27. Kallet RH, Branson RD. Should oxygen therapy be tightly regulated to minimize hyperoxia in critically ill patients? Respir Care 2016;61 (6):801-817.

28. Aboab J, Jonson B, Kouatchet A, Taille S, Niklason L, Brochard L. Effect of inspired oxygen fraction on alveolar de-recruitment in acute respiratory distress syndrome. Intensive Care Med 2006;32(12):19791986.

29. Meade MO, Cook DJ, Guyatt GH, Slutsky AS, Arabi YM, Cooper DJ, et al. Ventilation strategy using low tidal volumes, recruitment maneuvers, and high positive end-expiratory pressure for acute lung injury and acute respiratory distress syndrome: a randomized controlled trial. JAMA 2008;299(6):637-635.

30. Ferguson ND, Cook DJ, Guyatt GH, Mehta S, Hand L, Austin P, et al. High-frequency oscillation in early acute respiratory distress syndrome. N Engl J Med 2013;368(9):795-805.

31. Beitler JR, Sarge T, Banner-Goodspeed VM, Gong MN, Cook D, Novack V, et al; EPVent-2 Study Group. Effect of titrating positive end-expiratory pressure (PEEP) with an esophageal pressure-guided strategy versus an empirical high $\mathrm{PEEP}-\mathrm{FiO}_{2}$ strategy on death and days free from mechanical ventilation among patients with acute respiratory distress syndrome: a randomized clinical trial. JAMA 2019;321 (9):846-857.

32. Weinger MB, Lee LA. "No patient shall be harmed by opioid-induced respiratory depression": [proceedings of "essential monitoring strategies to detect clinically significant drug-induced respiratory depression in the postoperative period" conference]. Anesthesia Patient Safety Foundation Newsletter 2011;26:21-28.

33. The Joint Commission. Sentinel Event Alert 49: safe use of opioids in hospitals. 2012.

34. Jarzyna D, Jungquist CR, Pasero C, Willens JS, Nisbet A, Oakes L, et al. American Society for Pain Management nursing guidelines on monitoring for opioid-induced sedation and respiratory depression. Pain Manag Nurs 2011;12(3):118-145.e10.

35. Lamberti JP. Respiratory monitoring in general care units. Respir Care 2020;65(6):870-881. CrossRef: https://doi.org/10.4187/respcare.07405.

36. Taenzer AH, Perreard IM, MacKenzie T, McGrath SP. Characteristics of desaturation and respiratory rate in postoperative patients breathing room air versus supplemental oxygen: are they different? Anesth Analg 2018;126(3):826-832.

37. Lam T, Nagappa M, Wong J, Singh M, Wong D, Chung F. Continuous pulse oximetry and capnograpy monitoring for postoperative respiratory depression and adverse events: a systematic review and meta-analysis. Anesth Analg 2017;125(6):2019-2029.

38. Kisner D, Wilhelm MJ, Messerli MS, Zünd G, Genoni M. Reduced incidence of atrial fibrillation after cardiac surgery by continuous wireless monitoring of oxygen saturation on the normal ward and resultant oxygen therapy for hypoxia. Eur J Cardiothorac Surg 2009;35(1):111115.

39. Gaunt KA, Spilman SK, Halub ME, Jackson JA, Lamb KD, Sahr SM High-flow nasal cannula in a mixed adult ICU. Respir Care 2015;60 (10):1383-1389

40. Lamb KD, Spilman SK, Oetting TW, Jackson JA, Trump MW, Sahr SM. Proactive use of high-flow nasal cannula with critically ill subjects. Respir Care 2018;63(3):259-266.

41. Bell N, Hutchinson CL, Green TC, Rogan E, Bein KJ, Dinh MM. Randomized control trial of humidified high-flow nasal cannula versus standard oxygen in the emergency department. Emerg Med Australas 2015;27(6):537-541.

42. Rittayamai N, Tscheikuna J, Praphruetkit N, Kijpinyochai S. Use of high-flow nasal cannula for acute dyspnea and hypoxemia in the emergency department. Respir Care 2015;60(10):1377-1382.

43. Makdee O, Monsomboon A, Surabenjawong U, Praphruetkit N, Chaisirin W, Chakorn T, et al. High-flow nasal cannula versus conventional oxygen therapy in emergency department patients with cardiogenic pulmonary edema: a randomized controlled trial. Ann Emerg Med 2017;70(4):465-472.

44. Jones PG, Kamona S, Doran O, Sawtell F, Wilsher M. Randomized controlled trial of humidified high-flow nasal oxygen for acute respiratory distress in the emergency department: the HOT-ER study. Respir Care 2016;61(3):291-299.

45. Zochios V, Collier T, Blaudszun G, Butchart A, Earwaker M, Jones N, Klein AA. The effect of high-flow nasal oxygen on hospital length of stay in cardiac surgical patients at high risk for respiratory complications: a randomized controlled trial. Anaesthesia 2018;73(12):14781488.

46. Vourc'h M, Nicolet J, Volteau C, Caubert L, Chabbert C, Lepoivre T, et al. High-flow therapy by nasal cannula versus high-flow face mask in severe hypoxemia after cardiac surgery: a single-center randomized controlled study-the HEART FLOW study. J Cardiothorac Vas Anesth 2020;34(1):157-165.

47. Yu Y, Qian X, Liu C, Zhu C. Effect of high-flow nasal cannula versus conventional oxygen therapy for patients with thoracoscopic lobectomy after extubation. Can Respir J 2017;2017:1-8

48. Parke R, McGuinness S, Dixon R, Jull A. Open-label, phase 2 study of routine high-flow nasal oxygen therapy in cardiac surgical patients. $\mathrm{Br}$ J Anaesth 2013;111(6):925-931

49. Futier E, Paugam-Burtz C, Godet T, Khoy-Ear L, Rozencwajg S, Delay JM, et al; OPERA study investigators. Effect of early postextubation high-flow nasal cannula versus conventional oxygen therapy on hypoxemia in patients after major abdominal surgery: a French multicenter randomized controlled trial (OPERA). Intensive Care Med 2016;42(12):1888-1898

50. Parke RL, McGuinness SP, Eccleston ML. A preliminary randomized controlled trial to assess effectiveness of nasal high-flow oxygen in intensive care patients. Respir Care 2011;56(3):265-270.

51. Frat J-P, Brugiere B, Ragot S, Chatellier D, Veinstein A, Goudet V, et al. Sequential application of oxygen therapy via high-flow nasal cannula and noninvasive ventilation in acute respiratory failure: an observational pilot study. Respir Care 2015;60(2):170-178.

52. Hernández G, Vaquero C, González P, Subira C, Frutos-Vivar F, Rialp G, et al. Effect of postextubation high-flow nasal cannula versus conventional oxygen therapy on re-intubation in low-risk patients: a randomized clinical trial. JAMA 2016;315(13):1354-1361.

53. Hou Q, Zhang Z, Lei T, Gan M, Wu X, Yue W, et al. Clinical efficacy of high-flow nasal humidified oxygen therapy in patients with hypoxemia. PLoS One 2019;14(6):e0216957.

54. Gaspari R, Spinazzola G, Ferrone G, Soave PM, Pintaudi G, Cutuli SL, et al. High-flow nasal cannula versus standard oxygen therapy after extubation in liver transplantation: a matched controlled study. Respir Care 2020;65(1):21-28. 


\section{AarC Clinical Practice Guideline: Managing Oxygen in Acute Care}

55. Matsuda W, Hagiwara A, Uemura T, et al. High-Flow Nasal Cannula May Not Reduce the Re-Intubation Rate Compared With a LargeVolume Nebulization-Based Humidifier. Respiratory Care 2020;65 (5):610-617.

56. Fernandez R, Subira C, Frutos-Vivar F, Rialp G, Laborda C, Masclans JR, et al. High-flow nasal cannula to prevent postextubation respiratory failure in high-risk nonhypercapnic patients: a randomized multicenter trial. Ann Intensive Care 2017;7(1):47.

57. Dhillon NK, Smith EJT, Ko A, Harada MY, Polevoi D, Liang R, et al. Extubation to high-flow nasal cannula in critically ill surgical patients. J Surg Res 2017;217:258-264.

58. Corley A, Bull T, Spooner AJ, Barnett AG, Fraser JF. Direct extubation onto high-flow nasal cannula postcardiac surgery versus standard treatment in patients with a $\mathrm{BMI} \geq 30$ : a randomized controlled trial. Intensive Care Med 2015;41(5):887-894.

59. Song HZ, Gu JX, Xiu HQ, Cui W, Zhang GS. The value of high-flow nasal cannula oxygen therapy after extubation in patients with acute respiratory failure. Clinics (Sao Paulo) 2017;72(09):562-567.

60. Lemiale V, Resche-Rigon M, Mokart D, Pène F, Argaud L, Mayaux J, et al. High-flow nasal cannula oxygenation in immunocompromised patients with acute hypoxemic respiratory failure: a Groupe de Recherche Respiratoire en Reanimation Onco-Hematologique study. Crit Care Med 2017;45(3):e274-e280

61. Frat J-P, Ragot S, Girault C, Perbet S, Prat G, Boulain T, et al; REVA Network. Effect of noninvasive oxygenation strategies in immunocompromised patients with severe acute respiratory failure: a post hoc analysis of a randomized trial. Lancet Respir Med 2016;4(8):646-652.

62. Lemiale V, Mokart D, Mayaux J, Lambert J, Rabbat A, Demoule A, Azoulay E. The effects of a 2-h trial of high-flow oxygen by nasal cannula versus Venturi mask in immunocompromised patients with hypoxemic acute respiratory failure: a multicenter randomized trial. Crit Care 2015; 19:380.

63. Azoulay E, Lemiale V, Mokart D, Nseir S, Argaud L, Pène F, et al. Effect of high-flow nasal oxygen versus standard oxygen on 28-day mortality in immunocompromised patients with acute respiratory failure: the HIGH randomized clinical trial. JAMA 2018;320(20):2099-2107.

64. Chanques G, Constantin JM, Sauter M, Jung B, Sebbane M, Verzilli D, et al. Discomfort associated with underhumidified high-flow oxygen therapy in critically ill patients. Intensive Care Med 2009;35(6):996-1003.

65. Cuquemelle E, Pham T, Papon J-F, Louis B, Danin P-E, Brochard L. Heated and humidified high-flow oxygen therapy reduces discomfort during hypoxemic respiratory failure. Respir Care 2012;57(10):15711577.

66. Mauri T, Galazzi A, Binda F, Masciopinto L, Corcione N, Carlesso E, et al. Impact of flow and temperature on patient comfort during respiratory support by high-flow nasal cannula. Crit Care 2018;22(1):120.

67. Poiroux L, Piquilloud L, Seegers V, Le Roy C, Colonval K, Agasse C, et al; REVA Network. Effect on comfort of administering bubblehumidified or dry oxygen: the Oxyrea noninferiority randomized study. Ann Intensive Care 2018;8(1):126.

68. Rochwerg B, Einav S, Chaudhuri D, Mancebo J, Mauri T, Helviz Y, et al. The role for high-flow nasal cannula as a respiratory support strategy in adults: a clinical practice guideline. Intensive Care Med 2020;46(12):2226-2237.

69. Yang PL, Yu JQ, Chen HB. High-flow nasal cannula for acute exacerbation of chronic obstructive pulmonary disease: a systematic review and meta-analysis. Heart Lung 2021;50(2):252-261. 